\title{
Preventing carbon monoxide exposures in long-term care facilities
}

\author{
Daniel Fong and Prabjit Barn \\ National Collaborating Centre for Environmental Health, BC Centre for Disease Control, Vancouver, BC
}

\section{Introduction}

Carbon monoxide $(\mathrm{CO})$ is a common but often neglected indoor air pollutant. Exposure to $\mathrm{CO}$ can lead to life-threatening cardiovascular and neurobehavioral effects; among these $\mathrm{CO}$ exposures are motor vehicle exhaust entering the home environment and inappropriate indoor use of fuel-burning appliances such as generators during power outages (Harduar-Morano et al. 2011, Goldman et al. 2014). Less is known about sub-acute exposures, particularly for persons who may be vulnerable to CO, such as residents in long-term care and other health care facilities.

The need to better understand and manage $\mathrm{CO}$ exposures in long-term care facilities arose from a 2010 incident where staff and residents were exposed to high levels of $\mathrm{CO}$ in a long-term care facility in Humboldt, Saskatchewan (Canadian Press 2014). The incident required the evacuation of one wing of the facility and contributed to three deaths. In response, the Saskatoon Health Region and the province of Saskatchewan have taken steps to ensure that such events are prevented. Funded by Health Canada, the National Collaborating Centre for Environmental Health (NCCEH) and BC Centre for Disease Control (BCCDC) are working with several partners, including Saskatoon Health Region, to conduct a five-year project that aims to provide a better understanding of $\mathrm{CO}$ effects among vulnerable persons and to support the development and implementation of measures to manage $\mathrm{CO}$ emissions and exposures in long-term care facilities.

\section{Sources of CO}

$\mathrm{CO}$ is a colourless, tasteless, and odourless gas formed through combustion processes. Indoors, $\mathrm{CO}$ can be released from fuelburning appliances when they are improperly installed, used, vented, or maintained; examples include generators, gas stoves, and boilers (World Health Organization 2010). Movement of $\mathrm{CO}$ from outdoor sources such as motor vehicles and industrial activity can also contribute to indoor exposure. Indoor $\mathrm{CO}$ concentrations are typically low, but concentrations can accumulate to harmful levels when persistent sources are present or when ventilation is low. Indoor CO exposures are particularly a concern in the winter months as air intakes and

Corresponding author: (contact@ncceh.ca) exhaust can be obstructed by snow or ice and when occupants are more likely to use fuel-burning appliances such as generators and charcoal grills indoors (Iqbal et al. 2012).

\section{Health effects of carbon monoxide}

The symptoms of $\mathrm{CO}$ exposure are nonspecific and vary depending on level and duration of exposure. Early symptoms can include headache, fatigue, nausea, vomiting, and dizziness (Raub et al. 2000). Continued exposure may result in unconsciousness, convulsions, and cardio-respiratory arrest. Individuals with heart disease are considered to be most vulnerable to $\mathrm{CO}$, but other underlying physiological conditions, such as those present in persons with respiratory disease or anemia, and being elderly can increase vulnerability.

The toxic effects of $\mathrm{CO}$ primarily arise from its ability to reduce oxygen content in the blood (i.e., hypoxic effects). Once inhaled, CO is absorbed across the lungs into the bloodstream where it binds to hemoglobin. As $\mathrm{CO}$ has a stronger affinity to hemoglobin than oxygen, the increased presence of CO-bound hemoglobin (carboxyhemoglobin, $\mathrm{COHb}$ ) limits the amount of oxygen-bound hemoglobin and diminishes the supply of available oxygen at tissue sites, thus leading to tissue hypoxia. $\mathrm{CO}$ also binds to other heme-containing molecules such as myoglobin, which is thought to further reduce oxygen delivery to tissues (World Health Organization 2010). Additionally, CO molecules may exert direct toxic effects on the brain (World Health Organization 2010). The percentage of $\mathrm{COHb}$ in blood is an indicator of both exposure and potential health effects (World Health Organization 2010). Physiological parameters that define $\mathrm{CO}$ uptake, $\mathrm{COHb}$ formation, and $\mathrm{CO}$ elimination are used to model the relationship between $\mathrm{CO}$ exposure and percentage $\mathrm{COHb}$ in blood (Gosselin et al. 2009).

\section{Moving towards a CO management framework for long-term care facilities}

The CO incident at the long-term care facility in Humboldt, Saskatchewan, brought forward important issues around protecting vulnerable persons from CO. First, because $\mathrm{CO}$ is a colourless and odourless gas, it can only be detected through monitoring. At the time of the incident, no $\mathrm{CO}$ detectors were 
installed or required in Saskatchewan health care facilities. Saskatoon Health Region now requires $\mathrm{CO}$ detectors to be installed in all health care facilities. Second, even if CO detectors had been in place in the facility, it is not clear if harmful exposures would have been prevented among vulnerable residents because of the threshold levels at which current $\mathrm{CO}$ detectors are set to alarm. In Canada, $\mathrm{CO}$ detectors are programmed to alarm once values of $70 \mathrm{ppm}$ within $1-4$ hours, $150 \mathrm{ppm}$ within $10-50$ minutes, or $400 \mathrm{ppm}$ within 4-15 minutes are reached (Canada Mortgage and Housing Corporation 2010). These alarm algorithms are based on exposures that correspond to a $\mathrm{COHb}$ blood level of $10 \%$; this is substantially higher than the $2 \% \mathrm{COHb}$ level on which Health Canada's indoor air guidelines for $\mathrm{CO}$ are based (Table 1) and well above levels at which persons most susceptible to $\mathrm{CO}$ may incur adverse health effects (Health Canada 2010). The 10\% COHb value is used in an effort to reduce the burden of nonemergency alarm events. Although this value is in line with $\mathrm{CO}$ detector alarms in other jurisdictions, including the United States and England, use of CO detectors alone may not be the best way to protect vulnerable groups from harmful $\mathrm{CO}$ exposures (Raub et al. 2000).

After the 2010 Humboldt incident, NCCEH/BCCDC were requested by Saskatoon Health Region to provide guidance on the establishment of a $\mathrm{CO}$ monitoring framework. $\mathrm{NCCEH} / \mathrm{BCCDC}$ identified several gaps in policy and practice, which limited the development of such a framework and approached Health Canada to request funding to carry out a $\mathrm{CO}$ project aimed at (i) synthesizing the current understanding of $\mathrm{CO}$ health effects among vulnerable populations; (ii) developing a health protective CO management framework that incorporates prevention, education, and monitoring activities and practical means to support their implementation; (iii) supporting the evaluation and knowledge transfer of $\mathrm{CO}$ management strategies; and (iv) fostering relationships between health agencies to address $\mathrm{CO}$ exposure risks in long-term care facilities. In addition to reviewing acute, sub-acute, and chronic health effects of $\mathrm{CO}$ among vulnerable individuals NCCEH/ BCCDC have worked with experts to conduct toxicokinetic modelling to understand the effects of specific physiological

Table 1. Health Canada indoor air guidelines for the general public for carbon monoxide (Health Canada 2010).

\begin{tabular}{|l|l|l|}
\hline $\begin{array}{l}\text { Averaging } \\
\text { period }\end{array}$ & $\begin{array}{l}\text { Guideline/ } \\
\text { limit } \mathbf{( p p m )}\end{array}$ & Comments \\
\hline 1 hour & 25 & $\begin{array}{l}\text { Light exercise. } \\
\text { Based on a critical effect of } \\
\text { reduction in maximum } \\
\text { duration of exercise in healthy } \\
\text { individuals. }\end{array}$ \\
\hline 24 hour & 10 & $\begin{array}{l}\text { Light exercise. } \\
\text { Based on a critical effect of } \\
\text { ST segment reduction in } \\
\text { individuals with coronary } \\
\text { heart disease. }\end{array}$ \\
\hline
\end{tabular}

vulnerabilities on the relationship between $\mathrm{CO}$ exposures and $\mathrm{COHb}$ in blood (National Collaborating Centre for Environmental Health 2014). In 2013, an expert group meeting was held to bring together experts from the Saskatoon Health Region, Health Canada, and the National Research Council, among others, to discuss research and practical issues around developing a $\mathrm{CO}$ management framework in long-term care settings.

\section{Current focus: evaluating a $\mathrm{CO}$ monitoring and reporting policy}

In 2013, the Saskatoon Health Region implemented a policy to mitigate the risk of harmful exposure to $\mathrm{CO}$ in long-term care facilities (Saskatoon Health Region 2013). This policy applies to all 38 regional health care facilities that provide overnight patient stays. The policy requires the mounting of $\mathrm{CO}$ detectors near fuel-burning appliances, daily monitoring and recording of $\mathrm{CO}$ levels, and initiation of specific steps if action levels are exceeded. The instantaneous and peak CO levels are recorded daily at each detector in each facility. Saskatoon Health Region uses an action level of $25 \mathrm{ppm}$ based on the Health Canada indoor air CO guidelines. If either value is at or above $25 \mathrm{ppm}$, the detector is reset to zero, a second reading is taken again in one hour, and a $\mathrm{CO}$ source investigation is initiated. If the monitor continues to read at or above $25 \mathrm{ppm}$, a "Code Brown" procedure is initiated, which may involve (but is not limited to) evacuation of the area and notification to the fire department, emergency medical services, and (or) utility providers.

NCCEH/BCCDC are assisting the Saskatoon Health Region to evaluate their $\mathrm{CO}$ monitoring and reporting policy. Using a participatory approach involving the Saskatoon Health Region, NCCEH/BCCDC, and a Credentialed Evaluator, the evaluation findings will help document the degree to which program activities are implemented and their capacity to manage $\mathrm{CO}$ risks in long-term care facilities. This processoriented, formative evaluation will be used primarily to identify facilitators and barriers to implementation as well as considerations for improving, modifying, or maintaining policies and procedures. Through this work, NCCEH/BCCDC plans to facilitate the exchange of knowledge between partners and health regions across Canada enabling them to implement similar CO monitoring and reporting frameworks. The results of these activities will be disseminated throughout Canada. Sharing operational implications and evaluation findings of CO management frameworks can help inform on the feasibility of preventive procedures and build capacity to respond to nonemergency and emergency incidents. Additionally, identifying and documenting opportunities to integrate $\mathrm{CO}$ risk management policies into the existing management of longterm care facilities could help with implementing $\mathrm{CO}$ risk reduction initiatives.

\section{Summary}

$\mathrm{CO}$ exposures and the negative health effects they cause are preventable. NCCEH/BCCDC and our partners, including 
the Saskatoon Health Region and Health Canada, are working to fill gaps in policy and practice related to $\mathrm{CO}$ prevention, education, and monitoring in long-term care facilities. Such initiatives will allow for the implementation of practical health protective measures to prevent $\mathrm{CO}$ exposures to vulnerable persons.

\section{Acknowledgements}

Production of this article has been made possible through a financial contribution from the Public Health Agency of Canada.

\section{References}

Canadian Press. 2014. Inquest wraps up into carbon monoxide deaths at Humboldt care home. Global News. 8 March. Available at http://globalnews.ca/news/1196054/inquest-wraps-up-into-carbonmonoxide-deaths-at-humboldt-care-home/.

Canada Mortgage and Housing Corporation. 2010. About your house: Carbon monoxide. Ottawa, ON: CMHC. Available at http://publications.gc.ca/collections/collection_2011/schl-cmhc/ nh18-24/NH18-24-25-2010-eng.pdf.

Goldman, A., Eggen, B., Golding, B., and Murray, V. 2014. The health impacts of windstorms: a systematic literature review. Public Health, 128(1): 3-28. doi: 10.1016/j.puhe.2013.09.022.

Gosselin, N.H., Brunet, R.C., and Carrier, G. 2009. Determination of carboxyhaemoglobin in humans following low-level exposures to carbon monoxide. Inhalation Toxicology, 21(13): 1077-1091. doi: $10.3109 / 08958370902744848$.
Harduar-Morano, L., and Watkins, S. 2011. Review of unintentional non-fire-related carbon monoxide poisoning morbidity and mortality in Florida, 1999-2007. Public Health Reports, 126(2): $240-250$.

Health Canada. 2010. Residential indoor air quality guideline: Carbon monoxide. Available at http://www.hc-sc.gc.ca/ewh-semt/ pubs/air/carbon_mono/index-eng.php.

Iqbal, S., Clower, J.H., Hernandez, S.A., Damon, S.A., and Yip, F.Y. 2012. A review of disaster-related carbon monoxide poisoning: surveillance, epidemiology, and opportunities for prevention. American Journal of Public Health, 102(10): 1957-1963. doi: 10.2105/ajph.2012.300674.

National Collaborating Centre for Environmental Health. 2014. Carbon monoxide monitoring in long term care faciliites and hospitals. Vancouver, BC: NCCEH. Available at http://www. ncceh.ca/content/carbon-monoxide-monitoring-long-term-carefacilities-and-hospitals. (Updated 17 August 2010; Accessed 19 April 2015).

Raub, J.A., Mathieu-Nolf, M., Hampson, N., and Thom, S. 2000. Carbon monoxide poisoning - a public health perspective. Toxicology, 145(1): 1-14. doi: 10.1016/s0300-483x(99)00217-6.

Saskatoon Health Region. 2013. Carbon monoxide monitoring and reporting - overnight stay facilities. Saskatoon, SK: Saskatoon Health Region. Available at https://www.saskatoonhealthregion.ca/ about/RWPolicies/7311-20-020.pdf.

World Health Organization. 2010. WHO guidelines for indoor air quality: Selected pollutants. Geneva: WHO. Available at http:// www.euro.who.int/_data/assets/pdf_file/0009/128169/e94535. pdf. 